\title{
CRIAÇÃO DA ESCOLA DE FORMAÇÃO DE PROFESSORES: IMPRENSA E AFIRMAÇÃO DE UMA CULTURA ESCOLAR
} (CAMPINAS, 1901-1903)

\author{
Leny Cristina S. S. Azevedo* \\ Ana Regina Pinheiro**
}

\begin{abstract}
RESUMO: Este texto apresenta alguns dos resultados de uma pesquisa que buscou compreender a história da Escola Normal "Carlos Gomes" de Campinas (SP), pela via das memórias dos documentos publicados pela imprensa campineira acerca da importância da criação da primeira instituição pública para formar professores para as séries iniciais do ensino. Os desdobramentos da correlação de forças estabelecida, nos tempos de 1901 a 1903, envolvendo políticos e intelectuais, foram registrados nos jornais campineiros na tentativa de se dar a conhecer, na escritura feita, não somente as normas institucionais e burocráticas que permearam os embates para a implementação da escola, como também os símbolos, valores e a pedagogia moral e cívica que acompanharam os movimentos pela expansão da educação. Busca-se analisar as relações entre imprensa e sociedade no processo de criação dessa escola, cujo modelo e tradição funcionaram como expressão da lógica de um Estado provedor, que consolida o direito de assegurar à população a expansão do ensino na cidade.
\end{abstract}

Palavras-chave: Memória. Escola. Imprensa campineira. Formação de professores. Cultura escolar.

* Doutora em Educação e professora adjunta da Faculdade de Educação da Universidade Federal do Rio de Janeiro (UFRJ).E-mail: leny.az@hotmail.com

** Doutora em Educação e professora do Instituto Luso-Brasileiro de Educação e Cultura. E-mail: aregin@uol.com.br 
THE CREATION OF THE TEACHER TRAINING COLLEgE: THE PRESS AND THE ASSERTION OF A SCHOOL CULTURE (CAMPINAS, 1901-1903)

ABSTRACT: This text presents some results from a research conducted to understand the history of the "Carlos Gomes Teacher Training College", in Campinas (sP, Brazil). It resorts to memories and documents published by the local press on the importance of the creation of the first public institution designed to train first grades teachers. The developments of a force correlation involving politicians and intellectuals, between 1901 and 1903, were reported in the press. This was intended to give information not only the institutional and bureaucratic norms, but also on the symbols, values and pedagogical aspects that accompanied the expansion of education. It then analyzes the relations between the press and the society in the process that led to create the "Carlos Gomes Teacher Training College", whose model and tradition expressed the logic of a Welfare State consolidating the right to expand teaching to the population of Campinas.

Key words: Memories. Press in Campinas. Teacher training. School culture.

Memória e imprensa: a criação da primeira escola para formar professores em Campinas

Escola Estadual "Carlos Gomes" faz parte da história de vida de
diferentes sujeitos que teceram suas memórias nos seus espaços
de ensino e da história da educação paulista, consolidando, de maneira emblemática, o projeto de institucionalização do ensino no estado de São Paulo, no início do período republicano.

Em um país que ainda não garantiu a educação pública de qualidade para todos, gratuita e democrática, o nascimento dessa escola para formar professores para o ensino das séries iniciais é, sem dúvida, um marco importante, prenunciador de conflitos e práticas que passaram pelo crivo dos preceitos científicos e dos agentes políticos e educacionais, à época. Atendendo aos anseios sociais em torno da necessidade de escolarização, como um dos requisitos à cidade que crescia e se urbanizava e que outrora fora o berço do republicanismo paulista, o projeto de implementação do ensino público em Campinas foi viabilizado pela Lei n. 861 , de 14 de dezembro de 1902, e concretizado com a inauguração 
da Escola Complementar de Campinas, em 13 de maio de 1903, tendo como seu primeiro diretor o professor Antonio Alves Aranha.

Desde sua fundação, as iniciativas que buscavam promover essa instituição foram alvo de numerosos registros no jornal Cidade de Campinas, que se tornou a principal fonte primária desse estudo, possibilitando a essa pesquisa perceber a existência de uma ampla mobilização social em defesa dessa escola. Em meio a disputas e tensões, a sociedade campineira postulou-a como uma vocação da cidade para o desenvolvimento e o progresso. Conseguiu, com sua implementação, em 1903, por um lado, garantir o cumprimento de um direito assegurado à população e da obrigação de incumbências educacionais atribuídas ao Estado; por outro, a instauração de um processo de homogeneização de práticas e saberes, a serem incorporados e ensinados pela escola (Souza, 1998)

A longa jornada dessa escola foi, segundo Nascimento (1999), em seu estudo sobre as "Memórias da educação: Campinas (1850-1960)", o objeto de sonhos e de orgulho dos campineiros. Demonstrando a permanência de sua tradição, os momentos singulares dessa história foram rememorados, quando a escola completou 100 anos, em 13 de maio de 2003, pela imprensa campineira, que acompanhou, em diferentes momentos, a trajetória do trabalho educativo realizado nessa instituição.

No momento em que se debate a formação docente e se questionam os saberes dessa prática pedagógica, torna-se relevante a recuperação do processo histórico que envolveu a ação do Estado e a relaçãao entre a cidade, a escola e a imprensa nas articulações em torno da fundação da primeira escola pública de Campinas para a formação de professores primários.

Para a compreensão desse momento, algumas questôes se fazem presentes: Em que medida a contribuição do espaço escolar de formação dimensionaria a carreira docente? Que papéis foram atribuídos pela imprensa à docência? Como se relacionam os fundamentos da tradição e a construção da ideia de direito à educação pública gratuita e universal disseminados pelos republicanos?

Para dar conta dessas discussōes, esse artigo procura analisar os discursos a respeito da importância da escola para a Cidade, pela via das memórias construídas no período de 1901 a 1903, explorando os sentidos que traduzem a construção da ideia da educação de tradição, disseminados pelos republicanos no jornal Cidade de Campinas. Esse 
ideário, de acordo com Carvalho (2003, p. 11), relaciona-se ao "imaginário republicano com a protagonização da escola como o signo da instauração de uma nova ordem, arma para efetuar o Progresso".

Com essa dimensão, é mostrada a expansão do ensino na cidade, o interesse para a afirmação da importância da educação pelos políticos e intelectuais, com ampla participação da imprensa local nos discursos que projetavam a relevância dos poderes públicos em assumirem a implementação desta escola em Campinas. É pertinente salientar que a matéria jornalística periódica é tomada, neste texto, como fonte de pesquisa e como artefato cultural. Dessa forma, além de ser um veículo de comunicação, que contribuía para informar a população e prestar-lhe contas sobre as práticas simbólicas realizadas no âmbito da instituição escolar, a imprensa é caracterizada como um espaço político, onde a elite republicana se articulava para propagar os valores e representações sociais relacionados à constituição da nacionalidade, à concepção de educação e dos saberes necessários à formação docente, legitimando o imaginário sociopolítico do momento.

De acordo com Alves (2007), até o início do século Xx, os jornais eram o principal meio de formação da opinião pública, principalmente a chamada "grande imprensa". Nesse período, as publicações ofereciam aos leitores uma quantidade de notícias nacionais e internacionais e tendiam a se enraizar, sobretudo no ambiente imediato e familiar, apresentando ao público os acontecimentos que pontuavam seu cotidiano e convidando-o a tomar uma posição ativa diante deles.

Como indica Cruz e Peixoto (2007, p. 258), "trata-se de entender a imprensa como linguagem constitutiva do social (...), desvendando, a cada momento, as relaçóes imprensa/sociedade, e os movimentos de constituição e instituição do social que esta relação propõe."

Imprensa: modelação e fabricação da necessidade de uma escola de formação de professores

Em 4 de março de 1901, o jornal Cidade de Campinas publicou a primeira iniciativa para conseguir a fundação dessa escola, quando, na Câmara Municipal, o vereador Carlos Kaysel propôs como necessidade real e urgente sua criação para formar professores. Foram documentados os contornos dessa história, assim publicada: 
A questão da prioridade da iniciativa, si cabe à Edilidade, a qualquer de seus dignos membros, ou ao directorio político, é, realmente, tão insignificante que não pode e nem deve pesar no ânimo de quem quer que seja. O que sim, todos devem collaborar para que se faça a creação da Escola Complementar, e no prazo mais breve possível, attendo-se ao número apreciavel de meninos e meninas que vão completando os cursos preliminares nos dois Grupos. (Cidade de Campinas, 2 de abril de 1901)

Destaca-se que a legislação do período prescrevia que a escola deveria ser gratuita e aberta a ambos os sexos, exigindo-se para ingresso a idade mínima de quinze anos e o certificado de conclusão da escola primária - ou aprovação no exame de admissão, no caso de candidatos que haviam recebido instrução em casa ou com professores particulares (Veiga, 2007).

Assim, preocupados em manter a população informada sobre o princípio de ser a escola um direito tanto do sexo feminino como do masculino, os mentores dos veículos de comunicação reivindicavam o investimento a ser feito para os campineiros. Também lamentavam a lentidão da tramitação desse processo e foram reveladas as argumentações das autoridades locais, colocando em foco as defesas políticas e uma imagem pública bem delineada. Quanto a atingir o público leitor com uma linguagem direta, o Dr. Rodrigues Alves (representante do "directorio" local) coroou esse momento de esforço voltado à defesa dos valores de uma tradição:

E para a consecução deste desideratum, resta apenas que de acordo com os termos da resposta do governo, a municipalidade envie àquelle uma estatística minuciosa da população escolar da cidade e município em que se demonstre a exequibilidade da medida proposta.

Consta que desse trabalho ficou encarregado o sr. Dr. Presidente da Câmara, de quem depende, portanto actualmente, o andamento deste negócio. Temos sobejos motivos para supôr que o digno representante do município, a quem se acha affecta a medida preliminar de que depende a realização de tão importante melhoramento, não se fará esperar, em providenciar no sentido de ficar o patriótico governo do Estado habilitado a agir consoante as nossas mais legítimas aspiraçôes. (Cidade de Campinas, 2 de abril de 1901).

A discussão sobre a construção da escola de formação de professores foi se aprofundando, na tentativa de difundir as aspirações e os 
anseios políticos quanto à formação profissional a ser propiciada pela Escola Complementar. Na redação, observa-se a importância de divulgar a informação como meio de tornar públicos os encaminhamentos feitos e, ao mesmo tempo, assinala-se o prestígio do meio de comunicação ao mostrar as manifestações feitas, socializando a luta pelos interesses públicos, o que fortalece o sentimento de civismo e de deveres para com a cidade, projetando, no discurso, um compromisso com a instrução.

Outro aspecto que se mostra relevante é a dimensão atribuída aos números relativos à população em idade escolar, que comprovariam a necessidade de implementar a escola graduada complementar em Campinas e justificariam, consequentemente, o investimento financeiro do Estado nesse empreendimento. E prosseguiu Alves:

Agradecemos aos cidadãos que compõem o directorio a deferência que nos dispensaram, permitindo que hoje offereçamos ao público o officio cujo theor é o seguinte:

Exmo, Sr.

O directorio do Partido Republicano de Campinas pede permissão para vir à presença de V. Exc. tomar uma parte do tempo precioso de que V. Exc. dispõe, para a administração de todos os ramos do serviço público do Estado, solicitando attenção e submettendo ao esclarecido critério de V. Exc. o assumpto deste offício.

Os que dirigem os negócios políticos de uma localidade tem o ineluctável dever de pugnar pela realisação das mais palpitantes necessidades públicas.

A direção política é uma comissão auxiliar do governo para o bem público, e sua missão ficaria de si mesma desmerecida, si apenas cogitasse dessas matérias, que constituem o que, se pode chamar o expediente dos partidos. Campinas, valha a verdade e diga a justiça, quer seguir essa directriz. (Cidade de Campinas, 9 de abril de 1901)

Além da ampliação da demanda escolar não atendida, as cogitações a respeito do grau de participação do Estado na tarefa de democratizar o ensino fizeram parte das pressões, no sentido de efetuar acordos para que o poder estadual pudesse se responsabilizar por parte dos dispêndios com o ensino.

Entre as necessidades claras e indiscutíveis que a sociedade campineira sente, uma há entre todas, que está exigindo a prompta satisfação da parte dos poderes públicos. 
Há no âmbito da cidade uma população escolar vastíssima que, enchendo os 2 Grupos Escolares, vae derramar as sobras para outras instituiçôes de, instrucção popular. A Santa Casa mantêm 500 meninas em suas aulas de instrucção primária; a Câmara Municipal tem as Escolas Ferreira Penteado e Correa de Mello, que sempre recolhem creanças dos dois sexos para instruir primariamente.

Coubem-se até agora as aulas dispersas ou isoladas, garantidas pelo poder público e os estabelecimentos curriculares, onde a infância recebe a melhor educação do espírito com as primeiras disciplinas escolares. Entretanto, completados os cursos dos Grupos Escolares, meninos e meninas, muitos dos quaes sem nenhuns elementos de fortuna, são forçados a não integrar os seus conhecimentos, porque não há em Campinas uma Escola Complementar, quando é certo, que outros nucleos de população menores e menos importantes são dotados desse inestimável melhoramento.

A sociedade campineira, que prima pela cordura de seus membros, pelo desejo de progredir e pelas nobres iniciativas de que têm dado provas exuberantes, tem o direito de possuir em seu seio uma instituição dessa, e que recolha os que completam os cursos iniciaes e querem continuar a receber a instrucção systhematica e ordenada, que o Estado dispensa aos seus filhos.

A V. Exc. que procura subir no conceito público, fazendo uma administração larga e ponderada, suggestionada pelos ditames do bem público geral, entregamos o pedido da população de Campinas para a creação de uma Escola Complementar.

Somos naturalmente o orgam politico incumbido de trazer aos poderes do Estado os reclames da população e da sociedade, em cujo meio desempenhamos a nossa missão. Queira V. Exc. deferi-la pela justiça que ella encerra e pelas alevantadas conveniências que satisfaz.

É a solicitação que o directorio do Partido Republicano de Campinas traz a presença do primeiro magistrado do Estado, por mediação do seu digno e illustre Secretário do Interior. (Cidade de Campinas, 9 de abril de 1901)

Percebemos, na declaração do presidente do Diretório do Partido Republicano de Campinas, a autodenominação de legítimos representantes da sociedade campineira e um discurso que articula a intenção de se completar a formação escolar com mais um nível de ensino ao profundo desejo da população dessa cidade de progredir e, ao mesmo tempo, possuir uma escola que recolha os (jovens) que pretendem continuar 
os estudos, atribuindo à educação um dos aspectos constitutivos do sujeito. Sendo intencional ou não, na revelação feita, a imagem construída quanto à infância e seu legado, ela referenda a nova face de excelência na formação como um orgulho e busca conferir à cidade seu lugar de pioneira, com a fundação de uma escola para formar professores. Procura-se conjugar liberdade e legalidade, evocando o papel educativo das instituições legais (Faria Filho, 2000).

Comuns ao período da institucionalização do ensino no estado de São Paulo, as orientações relativas à organização física do espaço escolar não foram secundarizadas no conjunto das reivindicações que visavam ao apoio da sociedade campineira, no que diz respeito à aprovação e ao investimento do Governo do Estado para a instalação da primeira escola pública na cidade. Dessa forma, o discurso recebeu total apoio, sendo acompanhado pelo jornal, que alerta para os cuidados que devem ser dispensados a esse ambiente.

Limpo, espaçoso, dotado de luz e ar suficientes, mas sem arabescos, arrendilhados, eis o que se exige para um estabelecimento dessa ordem.

E, como estamos discutindo e lembrando, apontaríamos como própria a casa de sobrado, na praça José Bonifácio, esquina da rua Francisco Glicério, pertencente ao espólio do finado major Francisco de Campos Andrade.

É um vasto prédio, com salóes magníficos, situado em optimo local, sem luxo, dependendo tão somente de pintura e pequenos retoques.

Tratando-se de bens de uma herança é de presumir que seja fácil sua aquisição ou locação, porque de ordinário, quando fallece, seus membros dispersam, não querendo continuar a residir em propriedade tão extensa.

Olhem os interessados para o assumpto pois que merece toda sua attenção. (Cidade de Campinas, 21 de julho de 1901)

A adequação da arquitetura do prédio às exigências e especificidades próprias de uma escola se mostrava tão importante quanto a necessidade de métodos, professores e alunos, colocando em primeiro plano a escolha de um espaço que contemplasse os preceitos higiênicos à época. Nesse sentido, a indicação a respeito de onde encontrar imóvel disponível demonstra a preocupação em estabelecer a escola em um ambiente diferenciado.

Enfim, o edifício deveria adequar-se ao seu destino e uma característica comum foi o aspecto de monumentabilidade das instituições 
republicanas, a exaltação do prédio como símbolo de renovação. De acordo, com o jornal, esse assunto não poderia ser esquecido, pois "esquecer é naufragar", revelando, assim, um sentimento de busca de melhoria social através da educação. $\mathrm{O}$ redator revela o olhar atento de quem identifica a mudança, os motivos e as intenções.

O político e advogado Dr. Antonio Álvares Lobo foi incumbido da apresentação e defesa do projeto de criação junto ao governo estadual. Nesse mesmo ano, obteve-se o parecer favorável do governo para a fundação da Escola Complementar, o que desencadeou, pelos vereadores de Campinas, a busca por um espaço apropriado, não existindo, até o final de 1901, previsão para essa inauguração.

A respeito desse momento, foi realizada a pesquisa no Arquivo Edgar Leunroth (AEL), que evidenciou o acompanhamento da imprensa para informar o assunto à população (Cidade de Campinas, 1901):

(...) neste momento dirigimos os rógos da população local ao sr. dr. Bento Bueno, de quem depende a instituição desse novo apparelho do ensino público.

Temos ouvido dizer que as jovens campineiras, que desejam cursar a Escola Complementar, não pretendem exercer o magistério, mas simplesmente integrar a sua educação intellectual. É um engano visível.

Que jovem há que possa dizer que não precisa de uma carta de professores, em vista de sua fortuna, no estado actual da sociedade brasileira?

Nenhuma, porque a riqueza material é coisa que vae e vem, como vão revoadas e voltam os ventos do ceo.

Além disso, é um argumento contrário à verdade. Grande número de meninas terminaram seus estudos nos Grupos, com summo aproveitamento, e se acha à espera da Escola Complementar para prosseguir nelles.

Algumas com sacrifício real de suas famílias, estão em São Paulo continuando o curso para serem professoras e outras aqui ficaram, porque não possuem recursos pecuniários e aguardam ainda a creação da Escola Complementar...

Pensamos que a Escola aqui deve ser mixta, para os dois sexos; mas a secção feminina pode e deve ser creada já, de preferência.

Quando nos perpassam pelo espírito os grandes tormentos da vida sempre enxergamos as mulheres como entes fracos e que mais necessitam de amparo para não se perderem em épocas de crises. 
Os homens têm um circulo muito mais amplo de acção, para procurarem um trabalho ou escolherem uma profissão. No sexo feminino essa escolha é, fatalmente, restricta, por força do natural melindre e da funcção que a elle cabe na sociedade. (Cidade de Campinas, 11 de setembro de 1901)

A força do discurso dirigido a Bento Bueno, Secretário do Interior, está em demonstrar a necessidade da implementação de uma escola mista, para a continuidade da formação dos jovens campineiros, com especial urgência e atenção para a seção feminina, cujas famílias se viam obrigadas a custear a continuidade de seus estudos na cidade de São Paulo. O artigo publicado em 1901 é, portanto, representativo quanto à compreensão do significado do papel da docência e sua relação com o universo feminino. Considerava-se que ter a "carta de professores" configurava um privilégio para as mulheres e que o curso deveria ser direcionado preferencialmente a elas.

Apesar de acentuar as capacidades e condições fisiológicas e psicológicas das mulheres, favoráveis ao exercício da docência, o discurso revela uma "definição de sua natureza", ressaltando que elas têm deveres a cumprir para com o Estado, transmitindo uma cultura e desempenhando a função simbólica de regeneradoras da Nação. Essa importante referência à necessidade das moças campineiras se profissionalizarem como professoras primárias, e exercerem efetivamente a docência, guarda relação com a preocupação que os legisladores então expressavam com o baixíssimo número de formandos, nos primeiros anos após as primeiras reformas do ensino paulista, de 1892 e 1893. Essas reformas, que previam a mudança curricular com ênfase em uma cultura enciclopédica e o objetivo declarado de elevar o nível de ensino oferecido pela Escola Normal de São Paulo, foram avaliadas por políticos e educadores, anos mais tarde, segundo Tanuri (1979), como medidas equivocadas, que se deformaram em idealizações, resultando em ensino de excelência, mas que formava pouquíssimos professores. Conforme podemos observar no discurso de José Feliciano de Oliveira, Secretário do Interior, em 1898:

Esta organização, dominada pela influência, então geralmente em voga, dos programas enciclopédicos revela da parte do nosso legislador o intuito patriótico de fundar em São Paulo um estabelecimento de ensino modelo, sem rival no país, e a par mesmo das escolas da Europa e da América do Norte. Parece-nos, entretanto, que a inspiração generosa foi muito além das condições do nosso meio; e dessa acentuada desproporção 
entre o ideal e a realidade sobre que ele tinha de atuar, proveio certo cunho de esterilidade que tem afetado a escola. Ela não tem podido preparar professores, não tem quase fornecido mestres, não obstante os esforços das hábeis direções que tem tido (Oliveira, 1898, apud Tanuri, 1979, p. 99)

Oliveira questionava a adequação para a realidade brasileira do ensino enciclopédico baseado nos modelos europeu e norte-americano. Queixava-se de que se consolidava o reconhecimento do alto padrão do ensino público paulista de formação de professores (tal qual almejaram os reformadores), na mesma proporção em que crescia o processo de elitização da escola pública paulista, resultando "certo cunho de esterilidade", refletido no baixo número de professores diplomados para lecionar nas escolas públicas primárias, contraditoriamente ao que demandava a sociedade paulista (Pinheiro, 2008).

O projeto de instalação de uma Escola Complementar em Campinas se fazia, então, acompanhado do discurso de incentivo para que as moças, ao fazerem o curso de magistério, tivessem a meta de desempenhar as funçóes docentes. Contudo, outro aspecto que se mostrava polêmico era a visão das qualidades que as diferenciavam das qualidades masculinas, pois se assiste a argumentações que confirmam sua inferioridade como "entes fracos". Ao mesmo tempo, é possível enquadrá-las na transição da esfera doméstica para o domínio público, permitindo, assim, a realização de um trabalho.

Constata-se, com isso, o reforço de uma tradição para o ensino das primeiras séries quanto à profissionalização associada a uma tarefa feminina, sobressaindo seus potenciais naturais relacionados aos "melindres" femininos, o que direcionava para serem consideradas as melhores educadoras para o trabalho pedagógico com as crianças, em que o amor, a doçura, as atitudes de preocupação e cuidado com os outros seriam as vias socialmente aceitáveis para desenvolver as atividades educativas. Essa visão ingênua desviava o foco de um dos possíveis desdobramentos ocasionados pelo baixo número de professores que se formavam na Escola Normal de São Paulo; mas, por outro lado, chamava a atenção para a permanência da idealização, que exerce relevante papel, relacionada à homogeneização de valores acerca da profissão docente.

Ainda percebemos, hoje, a predominância feminina nas séries iniciais do ensino, obedecendo à dinâmica em que as mulheres ganharam espaço, segundo Nunes (2007), participando de alguma forma das 
regras do jogo do mercado de trabalho e dos círculos de prestígio e poder. No início do século Xx, defendia-se uma educação feminina nos princípios do decoro, da tradição e, de acordo com a autora, a professora exemplar seria apreciada se conjugasse harmoniosamente também os deveres da "filha respeitosa", da "esposa honrada" e da "mãe dedicada". Em outras palavras, a profissão docente era aceita para as mulheres pela proximidade entre a escola e o ambiente familiar (Nunes, op. cit., p. 118123). Entretanto, o que foi mudando aos poucos foi a constituição de espaços de formação que dimensionaram a docência, uma vez que aumentou o número de professoras que puderam investir no aperfeiçoamento de sua prática e contribuíram para a discussão dos diferentes papéis atribuídos à carreira, com o intuito de questionar as memórias construídas que ainda permeiam a identidade do magistério como uma ação de amor e vocação.

Nota-se que essa percepção está nos discursos dos intelectuais, educadores e políticos no início do século Xx, para a criação da Escola Normal. A imprensa legitimava a necessidade de conferir prioridade ao ensino, divulgando, em 1902, as iniciativas que aconteceram com as eleições para vereadores, visando acelerar a autorização do governo do Estado para viabilizar a formação profissional dos jovens candidatos à docência. Uma dessas iniciativas foi a liberação de verba para ser locado o prédio que iria comportar os primeiros alunos do curso.

No jornal Cidade de Campinas, foram comunicadas as providências para a reforma do prédio e informaram-se os dispositivos encaminhados pela Câmara Municipal de Campinas, através de um ofício, ao governo estadual, ao se dar o encerramento da reforma. O secretário do Interior enviou a Campinas, em 8 de maio de 1902, o Sr Antonio Rodrigues Pereira, com o objetivo de avaliar as condições do prédio e sua apropriação para a instalação da escola. Ao final da visita, recomendou-se a instalação, pois a adaptação atendia às necessidades iniciais para receber as primeiras turmas do curso de formação de professores.

Na Câmara de Deputados, em São Paulo, instalou-se uma disputa entre os políticos de Campinas e de Ribeirão Preto para conseguir a instalação da escola. Saiu vitoriosa Campinas, por já ter o prédio para abrigar as primeiras turmas, pelas condições de expansão comercial, agrícola e sanitária. Também se ligavam afetivamente a Campinas o secretário do Interior (Bento Bueno) e o governador do Estado (Bernardino de 
Campos), que passaram a juventude fazendo amigos na cidade (Nascimento, 1999).

No final do ano de 1902, com a Lei n. 861 (12/12/1902), a cidade de Campinas conseguiu autorização para instalação da Escola Complementar, após uma longa jornada de impasses e reivindicaçóes, conforme se pode observar ao longo das ações aqui expostas anteriormente. Essas repercussôes revelam a história dos movimentos políticos e sociais que imprimiram discursos e práticas preocupados em vincular progresso, educação e transformação da realidade social. Houve um movimento de mão dupla, ou seja, esses não eram valores emanados do Estado nacional, visto de forma absoluta, mas estavam na pauta de reivindicaçōes dos movimentos sociais que almejavam a instalação e ampliação da escolarização. Para Nascimento (1999), como Escola Complementar de Campinas (1903-1911), o objetivo foi ampliar e completar o ensino ministrado nas escolas preliminares (ensino primário obrigatório e gratuito, regido por professores diplomados). Depois, tendo em vista a falta de professores preliminares, os concluintes de escolas complementares que passassem pelo estágio prático numa das escolas-modelo, ou num dos Grupos Escolares, obteriam um diploma que os habilitava ao magistério preliminar.

Foi nomeado para a direção da Escola Complementar o Sr. Antonio Alves Aranha, em 3 de fevereiro de 1903; em 5 de fevereiro, foi publicado o edital para a composição do quadro docente. Os professores nomeados em 12 de fevereiro pelo diretor foram: João de Barros, João Marcílio, Arthur Segurado e a professora Escolástica do Couto Aranha (esposa do diretor). Amaral (1927) relata, em "Escola Normal", as características profissionais e pessoais do primeiro diretor nomeado:

Foi nomeado director da Escola Complementar o antigo professor Antonio Alves Aranha. Havia muito tempo que elle se dedicava de corpo e alma ao magistério. Trazia, pois, consigo essa credencial, alliada a um espírito esclarecido e ao coração affectivo, predicados estes que o caracterisavam. Excessivamente escrupuloso, dedicado ao trabalho e, às vezes, tímido, tomava, todavia, com firmeza as suas resoluçōes, sempre pautadas por uma honestidade impolluta.

Assinala-se, neste registro, o caráter e a competência inquestionável do professor que enaltecerá o nascimento da Escola. A inauguração foi preparada pelas autoridades públicas com apreço, visando reforçar 
Criação da escola de formação de professores...

a importância desse estabelecimento para os campineiros. Sob o título "Festa significativa", projeta-se o retrato de uma época:

(...) a cerimônia inaugural desse instituto é, portanto, uma verdadeira festa para a família campineira e a data de sua celebração bem merece coincidir com a da lei áurea, que "redimiu os captivo", porque nas escolas se redimem as creanças do perigoso captiveiro da ignorância. (Cidade de Campinas, 13 de maio de1903)

Com o uso desse discurso, foi-se empreendendo uma tradição do Estado republicano que ambicionava libertar os jovens através da educação, combinando os aspectos moral, intelectual e social, deixando entrever a urgência da execução de novas políticas para gerir a sociedade. A fundação de institutos de ensino fazia parte da construção da imagem de crianças que deveriam ser valorizadas (Monarcha, 1989).

Em 15 de maio de 1903, no jornal Cidade de Campinas, foi retratado o desdobramento do envolvimento da sociedade na festividade, com o artigo denominado "A inauguração". Foi documentada a descrição da festa e o envolvimento de diferentes personalidades na solenidade da Fundação da Escola Complementar. Com essa descrição, é possível perceber a organização do ato de celebração, pois, no registro minucioso feito no jornal, é revelado o tempo, o conteúdo dos discursos e o cuidado com a estética para o cumprimento das formalidades, entre outros aspectos.

O director e professores da Escola Complementar de Campinas, desejando dar uma prova de reconhecimento pelos inestimáveis serviços prestados por v. ex. à esta Escola, já como homem público, já como particular, auxiliando-os na festa do Estabelecimento, tomam a liberdade de offerecer a v. exc., como testemunho de eterna gratidão, a penna com que foi assignado pelo exmo. sr. Dr. Secretário do Interior a acta de sessão inaugural da mesma Escola. (Cidade de Campinas, 15 de maio de 1903)

Voltar o olhar para o gesto do diretor e dos professores é buscar compreender as relações que se estabeleceram com essa ação. Graças ao intercâmbio simbólico promovido através do presente (a pena), faz-se a comunicação sobre os bens prestados; na narrativa construída no relato da época, observa-se, no texto publicado pela imprensa, a memória que se quer resguardar, ou seja, o reconhecimento dos envolvidos e 
o agradecimento à autoridade que concebe uma necessidade básica a cidade. A consolidação do afeto é firmada de forma acolhedora, com certa conotação emocional, apoiada na valorização da imagem que confere a posse dos direitos por meio do símbolo. A alegria, a concórdia, a generosidade, o respeito à figura do político compóem a estrutura afetiva e harmônica representada no texto.

Tal visão pode ser qualificada de ingênua, conhecendo as críticas aos sistemas herdados que isolaram a busca de projetos de organização escolar e convivência na instituição de ensino e, principalmente, tornaram difíceis a concretização de uma formação docente de qualidade e a tão aclamada valorização do professor. Com toda a carga histórica, basta atentar para a atualidade, para visualizarmos as diferenças existentes entre os sistemas efetivos de escolarização e aqueles que não os têm (Azevedo, 2008).

Visualiza-se, assim, a complexidade que envolveu as relações sociais, políticas, materiais e educacionais, que trouxe marcas à fundação da Escola Complementar e que se busca refletir, seguindo o trajeto sinuoso, solitário e desafiante da sua natureza. Nesse labirinto de propostas, discursos, interesses, sonhos, esperanças, sociabilidades e afetividades é que necessitamos fazer a travessia para outra perspectiva, que movimenta e transforma o vivido e vivente, conforme nos inspira o poeta Carlos Drumond de Andrade (1962):

\author{
Um inseto cava \\ Cava sem alarme \\ Perfurando a terra \\ Sem achar escape. \\ Que fazer, exausto, \\ Em país bloqueado, \\ Enlace de noite, \\ Raiz e minério? \\ Eis que o labirinto \\ (Oh razão, mistério) \\ Presto se desata: \\ Em verde, sozinha, \\ Antieuclidiana, \\ Uma ORQUÍDEA forma-se.
}




\section{Referências}

ALVES, A. A imprensa na cidade de Santos: 1849-1930. Projeto História: Revista de Estudos Pós-Graduandos em História e do Departamento de História da PUC-SP, São Paulo, n. 35, p. 39-62, dez. 2007.

AMARAL, L. Escola Normal. In: CAMPINAS recordações. São Paulo: Secção de Obras D’ O Estado de São Paulo, 1927.

ANDRADE, C.D. Áporo. In: Andrade, C.D. Antologia poética. Rio de Janeiro: Record, 1962.

AZEVEDO, L. Escola Normal "Carlos Gomes": memória e formação de professores. 2005. Tese (Doutorado em Educação) - Faculdade de Educação, Universidade Estadual de Campinas, Campinas.

AZEVEDO, L. A constituição de "ser professor" em Campinas-SP nas primeiras décadas do século XX: memórias de um passado glorioso. Bragança Paulista: EDUSF, 2007.

CARVALHO, M.M.C. A escola e a república e outros ensaios. Bragança Paulista: EDUSF, 2003.

CRUZ, H.F.; PEIXOTO, M.R.C. Na oficina do historiador: conversas sobre história e imprensa. Projeto História: Revista de Estudos PósGraduandos em História e do Departamento de História da PUC-SP, São Paulo, n. 35, p. 253-270, dez. 2007.

FARIA FILHO, L.M. Dos pardieiros aos palácios: cultura escolar e urbana em Belo Horizonte na Primeira República. Passo Fundo: Upf, 1999.

FARIA FILHO, L.M. Os tempos e os espaços escolares no processo de institucionalização da escola primária no Brasil. Revista Brasileira de Educação, Campinas, v. 1, n. 14, p. 19- 34, ago. 2000.

MONARCHA, C. A reinvenção da cidade e da multidão: dimensões da modernidade brasileira: a Escola Nova. São Paulo: Cortez; Campinas: Autores Associados, 1989.

MONARCHA, C. A Escola Normal da praça: o lado noturno das luzes. Campinas: EDUNICAMP, 1999. 
NASCIMENTO, T.A.Q.R. et al. Memórias da educação: Campinas (1850-1960). Campinas: EDUNICAMP; CMU, 1999.

NUNES, C. Formação docente: permanência do passado nos desafios do presente. In: SoUSA, J. Formação de professores para a educação básica: dez anos de LDB. Belo Horizonte: Autêntica, 2007. p. 118-123.

PINHEIRO, A.R. Escola Caetano de Campos: escola paulista, escola vanguardeira. 2008. Tese (Doutorado em Educação) - Faculdade de Educação, Universidade Estadual de Campinas, Campinas.

SOUZA, R.F. Templos de civilização: a implantação da escola primária graduada no estado de São Paulo (1890-1910). São Paulo: unesp, 1998.

TANURI, L.M. O ensino normal no Estado de São Paulo, 1890-1930. São Paulo: FE/Usp, 1979.

TANURI, L.M. Formação de professores. 500 anos de educação no Brasil. Revista Brasileira de Educação, Campinas, v. 1, n. 14, p. 61-88, 2000.

VEIGA, C. História da educação. São Paulo: Ática, 2007.

Recebido em agosto de 2010.

Aprovado em outubro 2010. 